\title{
Görsel analog skala kullanılarak dişeti estetiğinin değerlendirilmesi
}

\author{
Özge Çelik ${ }^{1}$, Orhan Hakkı Karataş², Sıddık Malkoç ${ }^{1}$
}

Selcuk Dent J, 2016; 3: 56-62

Başvuru Tarihi: 19 Şubat 2016 Yayına Kabul Tarihi: 15 Nisan 2016

\section{Öz \\ Görsel analog skala kullanılarak dişeti estetiğinin değerlendirilmesi}

Amaç: Fonksiyonel okluzyona eşlik eden çekici, hoş bir gülümseme başlıca ortodontik tedavi amacıdır. Bu çalışmanın amacı halktan insanlar (hasta velileri) tarafından gülümseme estetiğinde dişeti görünüm miktarının etkisini araştırmaktır.

Gereç ve Yöntemler: Çalıșmaya İnönü Üniversitesi Diş Hekimliği Fakültesi Ortodonti Anabilim Dalı'na başvuran 50 birey (25 erkek, 25 kadın; ortalama yas 39 ) katılımıștır. 11 görüntü sırayla en azdan en çoğa doğru dişeti görünümünün miktarına göre ayarlandı. Görsel Analog Skala (VAS) kullanılarak her gülüşün subjektif estetik değeri belirlendi. Estetik skor minimum 0 ve maksimum 100 olacak şekilde, 0 ve 100 arasında ayarlandı. Yapılan Kolmogorov-Smirnov testinde fotograflardan alınan puanların normal dağılıma uymadığı görüldü $(P<0,05)$. İstatistiksel analizlerde VAS skorları arasındaki farkı belirlemek için Kruskal-Wallis testi yapıldı. Fark yaratan grubu belirlemek için post hoc test olarak Bonferroni düzeltmeli Mann Whitney $U$ testi yapıldı. Kadınlar ve erkekler arasındaki farkı belirlemede Mann Whitney $U$ testi kullanıldı.

Bulgular: İstatiksel analiz, görsel analog skala skorlarının dişeti görünüm miktarından önemli şekilde etkilendiğini göstermektedir $(P<0,001)$. Ancak skorlamayı yapan kadınlar ve erkekler arasında estetik skorları arasında fark yoktur $(P>0,05)$. En çok beğenilen görüntü 0 mm'lik dişeti görünümü olan resimdir $(\mathrm{P}<0,001)$.

Sonuç: Estetik skorlamada görsel analog skala kullanılmak ile basit, hızlı ve tekrarlanabilir sonuç elde edilebildiğinden tavsiye edilmektedir. Halktan bireyler $0 \quad \mathrm{~mm}$ 'lik dişeti görünümünü en çekici olarak nitelendirmektedirler.

\section{ANAHTAR KELIMELER}

Dişeti, görsel analog skalası, gülümseme

Estetik, güzelliğe ilgi ya da güzellik beğenisi anlamına gelmektedir (Krishnan ve ark. 2008). Modern diş hekimliğinde estetik giderek daha büyük öneme sahip olmaktadır. Televizyon programları ve görsel medya, seyircilere güzel yüz

\section{ABSTRACT}

The evaluation of gingival aesthetic using visual analogue scale (VAS)

Background: An attractive, well-balanced smile is a highly regarded orthodontic treatment objective, along with creating a functional occlusion. The aim of this investigation was to assess the influence of the amount of gingival display on smile aesthetics evaluated by lay person (parents of the patients).

Methods: The smile raters were 50 parents $(25$ males, 25 females; mean age 39 years) who attended to Inonu University, Faculty of Dentistry, Department of Orthodontics, Malatya, Turkey. Eleven images were arranged in order of the amount of gingival display, from the least to the most. Determination of the subjective aesthetic value each smile was made using a visual analogue scale (VAS). The aesthetic score was distributed from 0 to 100,0 being the minimum and 100 the maximum aesthetic value. Normality for continued variables in groups was determined by the Kolmogorov-Smirnov test. The variables did not show normal distribution $(P<0,05)$. So, KruskalWallis test was used for comparison of variables between the VAS scores among the photographs. Mann-Whitney $U$ Test was conducted as the post hoc test after Bonferroni correction to determine the group which differs from others. And, Mann-Whitney $U$ test was used to assess the difference between the males and females.

Results: Statistical analysis demonstrated that VAS scores significantly affected by amount of gingival display $(P<0,001)$, however there was no significant difference in aesthetic scores between the male and the female raters $(P>0,05)$. The image which is $0 \mathrm{~mm}$ gingival display was given the highest score $(P<0,001)$.

Conclusion: Use of the VAS method in scoring aesthetics should provide simple, rapid, and reproducible results. The smile with $0 \mathrm{~mm}$ of gingiva was considered to be the most attractive by the lay person.

\section{KEYWORDS}

Gingiva, visual analogue scale, smiling

ve mükemmel gülüşü dayatacak yayınlar yapmaktadır. Böylece son zamanlarda insanların estetik görünüşüne verdiği önem artırmıştır. Hastalar genellikle estetik sebeplerle diş tedavisi olmak istemektedir. Ancak güzellik kesin bir kavram değildir ve özneldir. Kültüre, etnik

\footnotetext{
1 İnönü Üniversitesi Diş Hekimliği Fakültesi Ortodonti Anabilim Dalı, Malatya

2 Afyon Kocatepe Üniversitesi Diş Hekimliği Fakültesi Ortodonti Anabilim Dalı, Afyon
} 
faktörlere ve bireysel tercihlere göre değişmektedir (Tjan ve ark. 1984).

Gülümseme yüz ifadesinde çok önemli bir rol oynar. Kişisel gelişim uzmanı Amerikalı yazar Dale Carnegie, insanları etkilemenin en etkili yönteminin gülümseme olduğunu belirtmiştir (Kokich ve ark. 1999). Çekici ve hoş bir gülümseme pozitif ilk etki oluştururken, sosyal yaşamda ikili ilişkilerde kişinin kabul görmesini sağlar.

İnsanlar iletişim halindeyken karşısındaki kişinin genelde gözleri ve ağzına odaklanır (Miller 1970). Goldstein, yüz çekiciliğinde gözlerden sonra gülümsemenin ikinci öneme sahip olduğunu ifade etmiştir (Goldstein 1969). $\mathrm{Bu}$ nedenle, çekici iyi bir gülümseme fonksiyonel okluzyonla beraber en önemli ortodontik tedavi hedeflerindendir.

Çekici bir gülümseme sadece diş boyutu, şekli, rengi ve pozisyona değil görünen dişeti miktarı ve dişlerin dudaklarla çevrelenmesine de bağlıdır (Van der Geld ve ark. 2007).

Tjan ve Miller gülümseme çizgisini; tüm maksiller keserlerin ve dişeti bandının tamamının izlendiği yüksek gülme hattı; maksiller keserlerin \%75-100 oranında izlendiği orta gülme hattı; maksiller keserlerin \%75'ten az izlendiği düşük gülme hattı olmak üzere üç tipe ayırmıştır (Tjan ve Miller 1984). "Artmış dişeti görünümü gülümsemenin etkisini azaltmaktadır. Ancak, Asya toplumunda bunu destekleyen hiçbir bilimsel veri olmamakla birlikte, Batı toplumunda, gülümsemede maksiller dişetinin 2 mm'den fazla görünmesi istenmemektedir (Fricker 1998).

Gummy smile; vertikal maksiller fazlalık, artmış overjet ve overbite, kısa üst dudak ve kısa keser kron uzunluğu gibi faktörlerin birleşiminin bir sonucudur (Allen 1988). Ancak Peck ve ark., üst dudak uzunluğu ve keser kron uzunluğunun bu faktörlere bağlı olmadığını rapor etmiştir (Peck ve ark. 1992).

Estetik algısı kişiden kişiye değişmekte ve kişisel deneyimler ve sosyal çevreyle şekillenmektedir (FloresMir ve ark. 2004). Aynı sebeple normal bireyler ve profesyoneller arasında güzellik hakkında farklı görüşler vardır (Albino ve ark. 1984). Bell ve ark. normal bireylerin dental uzmanların tercih ettiğinden daha doğal resimleri tercih ettiğini rapor etmişlerdir (Bell ve ark. 1985). PrahlAndersen ve ark., aynı gülümsemeler değerlendirildiğinde hastalar ve ortodontistler arasındaki görüş farkına dikkat çekmektedir (Prahl-Andersen ve ark. 1979). Son zamandaki çalışmalar ortodontist, diş hekimi ve normal bireyler arasında estetik algısında farklılık olduğunu doğrulamaktadır (Kokich ve ark. 1999, RodenJohnson ve ark. 2005).

Diş hekimleri için güzel ve çekici olan diğer bireylerin algısıyla uyuşmayabilmektedir (Giddon 1995). Diş hekimleri normal okluzyondan herhangi bir sapmayı çok daha fazla değerlendirmektedir (Shaw ve ark. 1975,
Prahl-Andersen 1978). Dental estetik konusunda toplumda bireysel algının araştırılması yoluyla, malokluzyonların estetik bozukluklarla ilişkisine odaklanılmaktadır (Katz 1978, Graber ve Lucker 1980). Uzun bir işlem olan ortodontik diagnoz hasta odaklı estetik diagnoz ve probleme dayalı tedavi planını içermelidir (Krishnan ve ark. 2008). Dudak kalınlığı, interkomissural genişlik, interlabial aralık, gülümseme indeksi ve dişeti yapısıyla belirlenen gülümsemenin görüntüsüne klinik muayene sırasında oldukça dikkat etmek gerekmektedir (Ackerman ve Ackerman 2002). Üst ve alt dudak gülümsemenin izlenen alanını çerçevelemektedir. Bu çerçevede gülümsemenin komponentleri, dişler ve dişeti bandıdır (Ackerman ve Ackerman 2002).

Peck ve Peck ortodontistlerin, yüz estetiğinin her zaman tüm insanları ilgilendiren bir konu olduğunu ve estetik değerlerin kaynağının sadece kendimiz değil insanlar olması gerektiğini unutma eğiliminde olduğunu ileri sürmüştür (Peck ve Peck 1970).

Kliniğe gelen hastaların öncelikli taleplerinin estetik doğrultusunda olması bu konuda hekimin değerlendirme yapmasını gerektirmektedir. Bu çalışmanın amacı, gülümseme estetiğinde dişeti görünümü miktarı algısının halktan bireyler üzerinde araştırılarak klinik uygulamalar sırasında profesyonel olmayan bir gözün gülümseme konusundaki düşüncelerine dikkat çekmektir.

\section{GEREÇ VE YÖNTEM}

Çalışmaya İnönü Üniversitesi Diş Hekimliği Fakültesi Ortodonti Anabilim Dalı'na başvuran 50 birey (25 erkek, 25 kadın; ortalama yaş 39) katıldı (Tablo 1). Bu bireyler hastaların velilerinden oluşmaktadır.

Tablo 1.

\section{Çalışmaya katılan gönüllülerin yaş dağılımları}

\begin{tabular}{|lcc|}
\hline & Erkek (n:25) & Kadın (n:25) \\
\hline Ort \pm SS (yaş) & $45,9 \pm 6,69$ & $36,8 \pm 4,86$ \\
\hline Median (yaş) & 46 & 36 \\
\hline Yaş Aralığı & $31-65$ & $24-48$ \\
\hline n: birey sayısı, Ort: Ortalama, SS: Standart sapma \\
\hline
\end{tabular}

Görsel Analog Skala (VAS) kullanılarak her gülüşün subjektif estetik değeri belirlendi. Bu değerlendirme skalası minimal kısıtlamalarla tasarlanmış olup en özgür kişisel cevap şeklidir. Bu amaçla skorlamadan önce bireylere çalışma hakkında mümkün olan en az bilgi verildi. VAS $100 \mathrm{~mm}$ uzunlukta olacak şekilde hazırlanarak, en az çekici ve en çekici olmak üzere her gülüş sıralanarak kişinin kendi estetik değerleriyle skorlaması yapıldı. 
Hastanın işaretlediği nokta ve 0 noktası arasındaki mesafe ölçülerek estetik skor elde edildi. Estetik skor 0100 arasında düzenlendi. 0 minimum, 100 maksimum estetik değeri ifade etmektedir.

Orijinal olarak iyi sıralanmış diş dizisine sahip bir kadın hastanın ağız içi fotoğrafı ve maksimum gülümseme sırasında çekilmiş cephe ağız dışı fotoğrafı kullanıldı. Bu fotoğrafta ideal olarak üst keser dişlerin insizal çizgisinden geçen hat, alt dudağın üst sınırına paralel uzanmaktaydı. Ayrıca üst keser dişler ve posteriora kadar uzanan molar dişlerden teğet geçen hat üst dudağın alt sınırıyla paralellik göstermekteydi (Resim 1). Görüntüler Adobe Photoshop CS6 (San Jose, California, USA) kullanılarak modifiye edildi.

Dişeti görünümü -5'ten 5'e kadar, $1 \mathrm{~mm}$ aralıklarla alt ve üst dudağın sınırladığı dudak çerçevesine dişlerin hareketiyle modifiye edildi. Gülümsemede üst dudağın sınırı 0'dan daha fazla olduğunda dişeti görünümü miktarı pozitif değer olarak belirlendi. Gülümsemenin üst dudak sınırı 0 mm'den az ise ölçüm negatif olarak belirlendi. 11 görüntü sırayla en azdan en çoğa doğru dişeti görünümünün miktarına göre ayarlandı. Her gülümsemede subjektif estetik değerin belirlenmesi görsel analog skala (VAS) kullanılarak kaydedildi.

\section{İstatiksel analiz}

Estetik skor minimum o ve maksimum 100 olacak şekilde, 0 ve 100 arasında ayarlandı. Yapılan Kolmogorov-Smirnov testinde fotoğraflardan alınan puanların normal dağılıma uymadığı görüldü $(P<0,05)$. İstatistiksel analizlerde VAS skorları arasındaki farkı belirlemek için Kruskal-Wallis testi yapıldı. Fark yaratan grubu belirlemek için post hoc test olarak Bonferroni düzeltmeli Mann Whitney U testi yapıldı. Kadınlar ve erkekler arasındaki farkı belirlemede Mann Whitney $U$ testi kullanıldı. Tüm değerlendirmelerde $\mathrm{P}<0,05$ düzeyi anlamlı kabul edildi. SPSS (versiyon 22.0) paket programı kullanılarak analiz yapıldı.

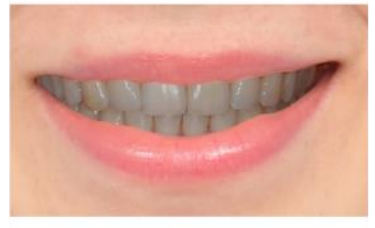

$-5 \mathrm{~mm}$

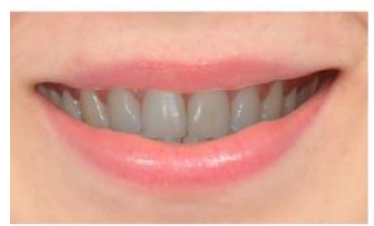

$-1 \mathrm{~mm}$

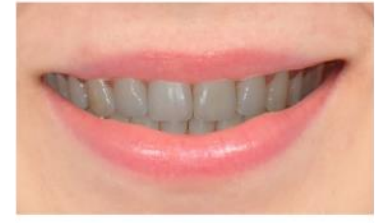

$-4 \mathrm{~mm}$

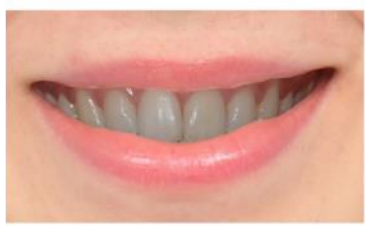

$0 \mathrm{~mm}$

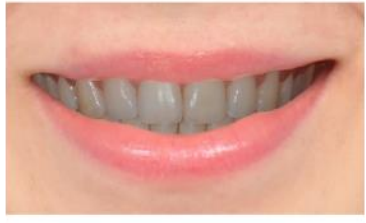

$-3 \mathrm{~mm}$

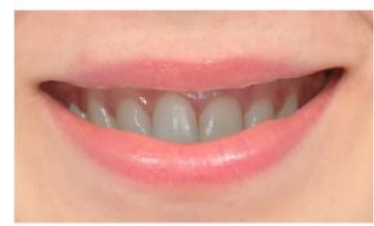

$1 \mathrm{~mm}$

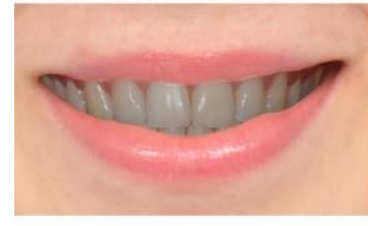

$-2 \mathrm{~mm}$

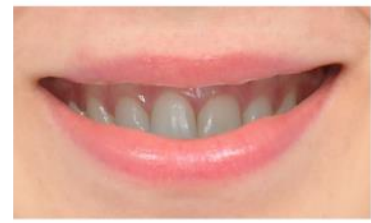

$2 \mathrm{~mm}$

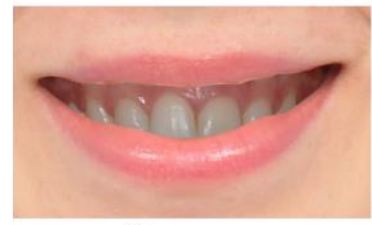

$3 \mathrm{~mm}$

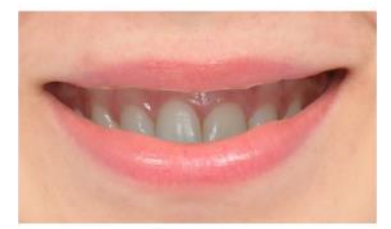

$4 \mathrm{~mm}$

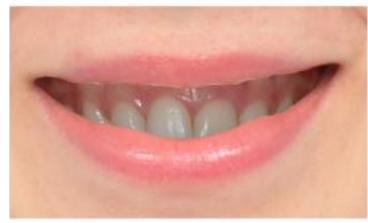

$5 \mathrm{~mm}$

Resim 1.

Dişeti görünüm miktarına göre sıralanmış 11 seri fotoğraf 


\section{BULGULAR}

İstatiksel analiz görsel analog skala skorlarının, dişeti görünüm miktarından önemli şekilde etkilendiğini göstermektedir $(P<0,001)$ (Tablo 2). Ancak skorlamayı yapan kadınlar ve erkekler arasında estetik skorları arasında fark yoktur $(P>0,05)$ (Tablo 3).

En çok beğenilen görüntü $64,4 \pm 36,3$ ortalamayla $0 \mathrm{~mm}$ 'lik dişeti görünümü olan fotoğraftır $(P<0,001)$ (Tablo 2$)$.

Tablo 2.

\section{Fotoğrafların aldığı puanların dağılımı}

\begin{tabular}{|c|c|c|c|c|}
\hline $\begin{array}{l}\text { Fotoğraf } \\
\text { Numarası }\end{array}$ & Ort & ss & $\S$ & $p$ \\
\hline 1 & 35,2 & 39,6 & $A B$ & \multirow{11}{*}{$\overline{8}$} \\
\hline 2 & 55 & 40 & BCD & \\
\hline 3 & 57,2 & 76,2 & $C D$ & \\
\hline 4 & 50 & 35 & BCD & \\
\hline 5 & 55,4 & 36,1 & $C D$ & \\
\hline 6 & 64,4 & 36,3 & $C D$ & \\
\hline 7 & 45,1 & 36,9 & $A B C D$ & \\
\hline 8 & 51 & 39 & $\mathrm{BCD}$ & \\
\hline 9 & 43,2 & 38,4 & $\mathrm{AC}$ & \\
\hline 10 & 32,2 & 37,5 & $A$ & \\
\hline 11 & 27,8 & 35,2 & A & \\
\hline
\end{tabular}

Ort: Ortalama, SS: Standart Sapma, § Kruskal-Wallis testine göre aynı harfi alan gruplar arasında fark yoktur.

\section{TARTIŞMA}

Görsel analog skala, ağrının subjektif ölçümünde kullanılan doğru, güvenilir ve tekrar edilebilen özellikteki bir yöntemdir (Ohnhaus ve Adler 1975). Birçok araştırmacı bu yöntemi estetik skorlaması yaparken çekiciliğin değerlendirilmesinde kullanmış ve basit ve hızlı bir yöntem olduğunu savunmuşlardır (Krishnan ve ark. 2008, Ritter ve ark. 2006).

Halktan bireylerin estetik konusundaki değerlendirme sonuçları diş hekimliği alanında çalışan bireylerin sonuçlarından oldukça farklıdır (Flores-Mir ve ark. 2004). Ortodontik tedavide hastanın algısını anlamak estetik konusunda tartışırken çok önemlidir. Bu nedenle çalışmamızda estetik değerlendirme yapmak için halktan bireyler seçildi.

Dudaklar, kişinin gülümsemesindeki diş, dişeti ve oral kavitenin oranını kontrol eden faktördür. Üst dudak gülümseme sırasında daha fazla yukarı doğru hareket ettiğinde, diş ve dişetleri daha fazla izlenecek ve bunların gülümsemedeki rolü daha da artacaktır. Gummy smile, genç erişkin erkeklerde \%7 ve genç erişkin kadınlarda \% 26 oranında görünmektedir (Moskowitz ve Nayyar 1995).

Çalışmamızda farklı seviyelerdeki dişeti görünümünün çekiciliğe etkisini karşılaştırdık. Gülümseme çekiciliğine maksiller dişeti görünümünün etkisinin değerlendirildiği Geron ve Atalia'nın çalışmasında, görüntüler $-4,6$ ile $3 \mathrm{~mm}$ arasında modifiye edilmiştir (Geron ve Atalia 2005). Bu çalışmadaki değerlendirilen aralık önceki çalışmalardan daha geniştir. Çalışmamızda değerlendirme aralığını artırarak skorlamayı yapan kişilerin farkındalığını ölçmeyi amaçladık.

Johnston ve ark. 92 sosyal bilimlerde okuyan öğrenci üzerinde alt yüz yüksekliğini değerlendirdikleri çalışmalarında, genç bireylerin estetik algısının daha eleştirel olduğunu saptamışlardır (Johnston ve ark 2005). Ancak Flores-Mir ve ark. gülümseme estetiğinin halktan bireyler arasında değerlendirdikleri çalışmalarında yaşın estetik algısında farklılık yaratmadığını bulmuşlardır (Flores-Mir ve ark. 2004). Çalışmamızda erkek bireylerin yaş ortalaması, kadın bireylerin yaş ortalamasından daha fazla olmasına rağmen kadın ve erkek bireylerin skorlama sonuçlarında anlamlı fark tespit edilmemiştir.

loi ve ark. estetik skorlamayı yapan kadın ve erkekler arasında fark olmadığını belirtmiştir (loi ve ark. 2010). Ancak Geron ve Atalia üst çenede dişeti görünümü açısından kadın ve erkek

Tablo 3.

Cinsiyete göre fotoğraflardan alınan puanların dağı̆ımı

\begin{tabular}{|c|c|c|c|c|c|c|c|c|c|c|c|c|}
\hline & 1 & 2 & 3 & 4 & 5 & 6 & 7 & 8 & 9 & 10 & 11 & Toplam \\
\hline & Ort $\pm S S$ & Ort $\pm S S$ & Ort $\pm S S$ & Ort $\pm S S$ & Ort $\pm S S$ & Ort \pm SS & Ort $\pm S S$ & Ort \pm SS & Ort $\pm S S$ & Ort $\pm S S$ & Ort $\pm S S$ & Ort $\pm S S$ \\
\hline Kadın & $34,6 \pm 37,3$ & $56,4 \pm 39,9$ & $60,2 \pm 37,6$ & $50,2 \pm 35,3$ & $64,3 \pm 33,3$ & $71,3 \pm 33,8$ & $42,0 \pm 36,1$ & $44,6 \pm 37,1$ & $29,3 \pm 34,4$ & $28,9 \pm 37,1$ & $20,7 \pm 33,4$ & $36,8 \pm 4,8$ \\
\hline Erkek & $35,8 \pm 42,6$ & $53,5 \pm 40,9$ & $54,2 \pm 36,4$ & $49,1 \pm 35,3$ & $46,5 \pm 37,1$ & $57,5 \pm 38,1$ & $48,3 \pm 38,2$ & $58,1 \pm 39,6$ & $57,1 \pm 37,9$ & $35,4 \pm 38,5$ & $34,8 \pm 36,2$ & $45,9 \pm 6,6$ \\
\hline P§ & 0,6 & 0,9 & 0,7 & 0,9 & 0,1 & 0,2 & 0,7 & 0,2 & $0,03^{*}$ & 0,7 & 0,1 & 0,66 \\
\hline
\end{tabular}


skorlama yapanlar arasında fark olduğunu, dişeti görünüm miktarına kadınların erkeklerden daha toleranslı olduğunu rapor etmişlerdir (Geron ve Atalia 2005). Moore (Moore ve ark. 2005) ve Parekh ve ark. (Parekh ve ark. 2006) yaptıkları çalışmalarda, erkek ve kadın skorlama yapanlar arasında fark olmadığını belirtmişlerdir. Bazı çalışmalar kadınların erkeklere göre çekicilikte daha fazla oylama eğiliminde olduklarını göstermiştir (Cochrane ve ark. 1999). Çalışmamızda skorlama yapan kadın ve erkekler arasında fark bulunmamıştır.

Kadınlarda daha genç bir görünüm sağlayan 1-2 mm'lik yüksek gülme hatlı dişeti görünümü daha belirgindir. Peck ve Peck ortodontik hastalar üzerinde yaptıkları çalışmada, gülümseme sırasında $\% 26$ oranında $2 \mathrm{~mm}$ veya daha fazla maksiller dişeti görünümü olduğunu bildirmişlerdir (Peck ve Peck 1970). Ioi ve ark.'nın yaptıkları çalışmaya göre ortodontist ve diş hekimliği öğrencileri 2 mm'lik dişeti görünümünün çekici olmadığı konusunda hemfikirdir (loi ve ark. 2010).

Kokich ve ark. kadın gülümsemelerini kullanarak yaptıkları çalışmada, halktan insanların 3 mm'ye kadar keser düzlemindeki eğimi fark edemediklerini ve ancak 4 mm'lik dişeti görünümünün çekici olmadığını fark ettiklerini bulmuşlardır (Kokich ve ark. 1999). Van der Geld ve ark.'na göre katılımcıların 2-4 mm aralığındaki gülümseme hattı yüksekliğinin en çok tercih edilen gülümseme hattı olduğu sonucuna varmışlardır (Van der Geld ve ark. 2007). Talic ve ark.'nın Suudi diş hekimleri ve halktan bireyler üzerinde yaptıkları çalışmaya göre 1 mm'den fazla olan dişeti dudak mesafesi olduğunda çekicilikte değişim olduğu sonucuna varmışlardır (Talic ve ark. 2013).

Geron ve Atalia halktan bireyler üzerinde dişeti görünümünün etkisini araştırdıkları çalışmalarında, en çekici gülümsemenin üst dudağın santral keserleri 0-2 mm örten görüntü olduğu sonucuna varmışlardır (Geron ve Atalia 2005). Ayrıca aynı çalışmada konuşma ve gülümseme sırasında estetik olmayan üst dişeti görünümü miktarının, maksiller santral keserlerin dişeti sınırının $1 \mathrm{~mm}$ üzerinde olduğu belirtilmiştir. Peck ve Peck'in maksimum gülümsemede santral keserlerin maksiller dişeti görünümünün $2 \mathrm{~mm}$ veya daha fazla olduğu dişeti gülümsemesi belirgin olan 27 erkek ve kadında yaptığı çalışmayla kıyaslandığında bu sonuçlar benzerdir (Peck ve Peck 1970). Kokich ve ark., kadın gülümsemelerini değerlendirdikleri çalışmalarında; halktan bireylerin $3 \mathrm{~mm}$ dişeti görünümünü estetik bulmadığı sonucuna varmışlardır (Kokich ve ark. 1999). Sonuçlardaki farklılıklar, farklı popülasyonların estetik algılarının farklı olmasından kaynaklanabilir.

Hunt ve ark.'nın yüzyirmi öğrenci üzerinde yaptıkları çalışmalarına göre maksiller dişeti görünümü kişinin gülümsemesindeki çekiciliği etkilemektedir (Hunt ve ark. 2002). Bu çalışmada 0-2 mm aralığındaki dişeti görünümü daha yüksek skorlar almıştır. Yaptığımız çalışmada $0 \mathrm{~mm}$ 'lik dişeti görünümü olan fotoğraf en yüksek skoru almıştır. Dişeti gülümsemesi değerlendirildiğinde halktan bireylerin algısı ortodontistlerden farklı olabilmektedir. Ortodontistlerin estetik algısı hastaların algısıyla uyumlu olmadığında sonuç hasta için kabul edilebilir olmayacaktır. $\mathrm{Bu}$ sebeple, ortodontik tedavi planı yaparken hastanın da katılımı oldukça önemlidir. Tedaviden sonra dişeti görünümünün aynı kalması durumunun hasta tarafından tatmin edici sonuçları engelleyeceği unutulmamalıdır.

Gülümseme analizi ve gülümseme tasarımı genelde iki çelişkili faktör arasında uzlaşma içermelidir: hasta ve ortodontistin estetik isteği ve hastanın anatomik ve fizyolojik sınırları. Estetik gülümseme tasarımı, klinisyene hastayı bireysel ve interdisipliner yaklaşımla tedavi etmesine izin veren multifaktöriyel karar alma sürecidir.

'Gummy smile tedavi edilmeli midir yoksa yaşla beraber dişeti görünümü etkisinin değişeceği düşünülerek bu durum beklenmeli midir' konusunda bir ikilem söz konusudur. Maksiller keserlerin dudakla örtülmesi yaşla beraber artma eğiliminde olup yüksek gülümseme hatları yaş arttıkça normal sınırlara ulaşabilmektedir (Vig ve Brundo 1978). Yaşla beraber üst keserlerin dudağı örtme miktarındaki artış, gummy smile olan bireyin gülümseme estetiğini düzeltir. Orta ya da düşük gülme hattında keser görünümü azaldığından daha yaşlı bir görünüm meydana gelmekte; bu da oral estetiği kötüleştirmektedir. Gummy smile'ı tedavi ederken bir diğer ikilem cinsiyet farklılığıdır. Van der Geld ve Van Waas'ın araştırmasına göre gülme hattı kadınlarda erkeklerden daha yukarıda konumlanmıştır (Van der Geld ve Van Waas 2003).

\section{SONUÇ}

Gülümseme estetiğinde dişeti çok önemli bir role sahiptir. Dişeti görünümünün azalması veya artması estetik olmayan görüntüye yol açmaktadır. Daha çekici bir gülümseme için ortodontik tedavi planı yapılırken bu konuya dikkat etmek gerekmektedir. Halktan bireyler 0 mm'lik dişeti görünümünü en çekici resim olarak nitelendirmektedirler. Dişeti görünümünü değerlendiren kadın ve erkekler arasında skorlama açısından fark yoktur.

Çalışmamızda dişeti görünüm miktarının değerlendirilmesi, kliniğe gelen hasta velilerine yapılan skorlama ile yapılmıştır. Illeriki çalışmalarda bu skorlamanın ortodontistler, diş hekimleri ve hastaları içerecek şekilde genişletilerek yapılması meslek grupları arasındaki algı farklılığının tespit edilmesi açısından yararlı olacaktır. 


\section{KAYNAKLAR}

Ackerman MB, Ackerman JL, 2002. Smile analysis and design in the digital era. J Clin Orthod, 36, 221-236.

Albino JE, Tedesco LA, Conny DJ, 1984. Patient perceptions of dentofacial esthetics: shared concerns in orthodontics and prosthodontics. J Prosthet Dent, 52, 913.

Allen E P, 1988. Use of mucogingival surgical procedures to enhance esthetics. Dental Clinics of North America, 32, 307-330.

Bell R, Kiyak HA, Joondeph DR, McNeill RW, Wallen TR, 1985. Perceptions of facial profile and their influence on the decision to undergo orthognathic surgery. Am J Orthod, 88, 323-332.

Cochrane SM, Cunningham SJ, Hunt NP, 1999. A comparison of the perception of facial profile by the general public and 3 groups of clinicians. Int $\mathrm{J}$ Adult Orthodon Orthognath Surgery, 14(4), 291-295.

Flores-Mir C, Silva E, Barriga MI, Lagravere MO, Major PW, 2004. Layperson's perception of smile aesthetics and facial views. J Orthod, 31, 204-209.

Fricker J P, 1998. Orthodontics and dentofacial orthopedics. Tidbinilla Pty Ltd Publishers, Canberra.

Geron S, Atalia W, 2005. Influence of sex on the perception of oral and smile esthetics with different gingival display and incisal plane inclination. Angle Orthod, 75, 778-784.

Giddon DB, 1995. Orthodontic applications of psychological and perceptual studies of facial esthetics. Semin Orthod, 1, 82-93.

Goldstein RE, 1969. Study of need for esthetics in dentistry. J Prosthet Dent, 2, 589-598.

Graber LW, Lucker GW, 1980. Dental esthetic selfevaluation and satisfaction. Am J Orthod, 77, 163-173.

Hunt O, Johnston C, Hepper P, Burden D, Stevenson M, 2002. The influence of maxillary gingival exposure on dental attractiveness ratings. Eur J Orthod, 24, 199-204.

loi, H, Nakata S, Counts AL, 2010. Influence of gingival display on smile aesthetics in Japanese. Eur J Orthod, 32(6), 633-637.

Johnston DJ, Hunt $\mathrm{O}$, Johnston $\mathrm{CD}$, Burden DJ, Stevenson M, Hepper $P, 2005$. The influence of the lower face vertical proportion on facial attractiveness. Eur $\mathrm{J}$ Orthod, 27, 349-354.

Katz RV, 1978. Relationships between eight orthodontic indices and an oral self-image satisfaction scale. Am J Orthod, 73, 328-334.
Kokich VO, Kiyak HA, Shapiro PA, 1999. Comparing the perception of dentists and laypeople to altered dental esthetics. J Esthet Dent, 11, 311-324.

Krishnan V, Daniel S, Lazar D, Asok A, 2008. Characterization of posed smile by using visual analog scale, smile arc, buccal corridor measures, and modified smile index. Am J Orthod Dentofacial Orthop, 133, 515-523.

Miller A G, 1970. Role of physical attractiveness in impression formation. Psychol Sci, 19, 241-243

Moore T, Southard KA, Casko JS, Qian F, Southard TE, 2005. Buccal corridors and smile esthetics. Am J Orthod Dentofacial Orthop, 127(2), 208-213.

Moskowitz M, Nayyar A, 1995. Determinants of dental esthetics: a rationale for smile analysis and treatment. Compend Contin Educ Dent, 16, 1164-1166.

Ohnhaus EE, Adler R, 1975. Methodological problems in the measurement of pain: a comparison between the verbal rating scale and the visual analogue scale. Pain, 1, 379384.

Parekh SM, Fields HW, Rosenstiel SF, Beck $F M, 2006$. Attractiveness of variations in the smile arc and buccal corridor spaces as judged by orthodontists and laymen. Angle Orthod, 76, 557-563.

Peck S, Peck H, 1970. A concept of facial esthetics. Angle Orthod, 40, 284-318.

Peck S, Peck L, Kataja M, 1992. The gingival smile line. Angle Orthod,62, 91-100.

Prahl-Andersen B, Boersma $\mathrm{H}$, Van der Linden FP, Mooer AW, 1979. Perceptions of dentofacial morphology by laypersons, general dentists and orthodontists. J Am Dent Assoc, 98, 209-12.

Prahl-Andersen B, 1978. The need for orthodontic treatment. Angle Orthod, 48, 1-9.

Ritter DE, Gandini LG, Pinto Ados S, Locks A, 2006. Esthetic influence of negative space in the buccal corridor during smiling. Angle Orthod, 76, 198-203.

Roden-Johnson D, Gallerano R, English J, 2005. The effects of buccal corridor spaces and arch form on smile esthetics. Am J Orthod Dentofacial Orthop, 127, 343-50. 
Shaw WC, Lewis HG, Robertson NR, 1975. Perception of malocclusion. Br Dent J, 138, 211-216.

Talic, N, AIOmar S, AIMaidhan A, 2013. Perception of Saudi dentists and lay people to altered smile esthetics. Saudi Dent J, 25, 13-21.

Tjan AH, Miller GD, 1984. Some esthetic factors in a smile. J Prosthet Dent, 51, 24-28

Van der Geld PA, Oosterveld P, Van Heck G, KuijpersJagtman AM, 2007. Smile attractiveness. Selfperception and influence on personality. Angle Orthod, 77, 759-765.

Van der Geld PA, Van Waas MA, 2003. The smile line, a literature search. Ned Tijdschr Tandheelkd, 1, 350354.

Vig RG, Brundo GC, 1978. The kinetics of anterior tooth display. J Prosthet Dent, 39, 502-504.

Yazışma Adresi:

Arş.Gör.Özge Çelik, İnönü Üniversitesi Diş Hekimliği Fakültesi

Ortodonti AD

Malatya, Türkiye

Tel : + 905393000737

E-mail: dt.celikozge@gmail.com 